\title{
Optimal Design of Multi-Span Pitched Roof Frames with Tapered Members
}

\author{
Ali Kaveh" ${ }^{*}$, Mohammad Zaman Kabir², Mahdi Bohlool² \\ ${ }^{1}$ Centre of Excellence for Fundamental Studies in Structural Engineering, School of Civil Engineering, \\ Iran University of Science and Technology, Narmak, Tehran-16, Iran \\ 2 Department of Civil Engineering, \\ Amirkabir University of Technology, Hafez Street, Tehran, Iran \\ * Corresponding author, e-mail: alikaveh@iust.ac.ir
}

Received: 09 September 2018, Accepted: 17 October 2018, Published online: 29 October 2018

\begin{abstract}
Many industrial buildings require large spans and high height, and the use of a frame with inclined roofs with non-prismatic elements can reduce the usage of steel. Pitched roof frame with single spans are optimized using different meta-heuristic algorithms. In this paper, the optimal design of industrial frames with two and three spans under gravity and lateral loads is performed. Five efficient and widely accepted optimization algorithms are used to optimize each frame. The convergence histories and design results of these algorithms are compared and the most suitable algorithm is determined. In each frame, the effect of increasing the apex height is evaluated on the optimal weight and the best angle is determined for optimum weight.
\end{abstract}

\section{Keywords}

optimal design, industrial frames, 2-span and 3-span, pitched roof frames, meta-heuristic algorithms

\section{Introduction}

In industrial structures due to the need for high elevation, inclined beams are often utilized. In these frames, the members of the frame are considered as non-prismatic to reduce the required material. The use of non-prismatic members in industrial structures with large spans has a significant effect on reducing the weight of the structure. In the past, many researchers have studied industrial structures. Some researchers have focused on designing these types of frames, and some other researchers studied the stability and behavior of the frame under various loads, and some of them optimum designed industrial structures. Among the researchers who have worked on optimum design of industrial frames, were O'Brien and Dixon [1]. They minimized the weight of a two-dimensional steel frame under the constraints of the Kinematic Theorem of plastic collapse using a linear programming method. Fraser [2] proved that non-uniform or haunched members are economic solutions for warehouses and factory buildings for a wide range of spans. Phan et al. [3] evaluated the effect of deflection limits on optimum weight. They optimized the frame weights with both ultimate and serviceability limit states, using a real-coded niching genetic algorithm. They concluded that real-coded niching genetic algorithm is effective and reliable. Phan et al. [4] evaluated the topographic effect on the weight or cost of the frame per meter length of building. They used real-coded genetic algorithm to optimize the portal frame. Saka [5] optimized the pitched roof steel frames with haunches for the rafters in the eaves. He used genetic algorithm to optimization. Saka determined optimum sections, also optimized the haunch height and haunch length in the eaves for more economical design. Kravanja et al. [6] optimized a single-story industrial building, taking into account the specifications of Eurocode. They used the mixed-integer non-linear programming (MINLP) to optimization. Avdelas [7] investigated the effect of the haunches in plastic analysis of frames using an elasto-plastic method. McKinstray et al. [8] optimized steel beams for large spans. They considered ultimate and serviceability limit states and used the genetic algorithm for optimum design. Kaveh et al. [9] compared some pitched roof frames with different tapered type utilizing different meta-heuristic algorithms. Kaveh and Ghafari [10] optimized single span pitched roof frames with nine meta-heuristic algorithms 
and compared their convergence histories and results. They also evaluated the effect of increasing the apex height and the tapered length on the optimum weight of the one span pitched roof frame.

\section{Structural design}

\subsection{Load combinations}

According to the ASCE7 specifications [11], the structure must be able to sustain the combination of the following loads:

$$
\begin{aligned}
& \text { 1.4DL } \\
& 1.2 \mathrm{DL}+0.5 \mathrm{SLR} \\
& 1.2 \mathrm{DL}+1.6 \mathrm{SLR}+0.5 \mathrm{WL} \\
& 1.2 \mathrm{DL}+\mathrm{WL}+0.5 \mathrm{SLR} \\
& 1.2 \mathrm{DL}+\mathrm{EL}+0.2 \mathrm{SL} \\
& \text { 0.9DL+EL }
\end{aligned}
$$

where DL, EL, WL are dead, earthquake, wind loads, respectively. SLR means SN or LR, where SN and LR are snow and roof live load.

\subsection{Analysis}

Structural analysis is performed taking into account the effects of $\mathrm{P}-\Delta$, and the second-order effects are considered by effective length method.

\subsection{Strength, stiffness and construction criteria}

a) According to AISC360-10 [12], the following conditions must be checked. Double symmetric section elements against minor and major bending and compression axial forces must satisfy the following equations:

$$
\begin{aligned}
& \frac{P_{u}}{\varphi_{a} P_{n}}+\frac{8}{9}\left(\frac{M_{u x}}{\varphi_{b} M_{n x}}+\frac{M_{u y}}{\varphi_{b} M_{n y}}\right)-1<0 \text { for } \frac{P_{u}}{\varphi_{a} P_{n}} \geq 0.2 \\
& \frac{P_{u}}{2 \varphi_{a} P_{n}}+\left(\frac{M_{u x}}{\varphi_{b} M_{n x}}+\frac{M_{u y}}{\varphi_{b} M_{n y}}\right)-1<0 \text { for } \frac{P_{u}}{\varphi_{a} P_{n}} \leq 0.2
\end{aligned}
$$

b) In the columns, the starting section must be smaller than or equal to the end section, and for the beams the middle section must be smaller than or equal to the two end sections.

$$
\begin{aligned}
& h_{1} \leq h_{2} \\
& h_{3}=\min \left\{h_{2}, h_{3}, h_{4}\right\}
\end{aligned}
$$

where $h_{1}, h_{2}$ are the height of the bottom and top of the column, $h_{3}$ and $h_{4}$ are height of the middle and end of the beam.
Table 1 Feasible range of variables

\begin{tabular}{lc}
\hline Variable & Feasible values \\
\hline Web height $(\mathrm{m})$ & $0.4,0.5,0.6,0.7,0.8,0.9,1,1.1,1.2$ \\
Web thickness $(\mathrm{m})$ & $0.008,0.01,0.012$ \\
Tapered length ratio (\%) & $0.1,0.15,0.2,0.25,0.3,0.35,0.4,0.45$ \\
Flange width (m) & 0.2 \\
Flange thickness (m) & 0.01 \\
\hline
\end{tabular}

\section{Problem definition}

\subsection{Objective function}

The objective function is defined as the total weight of the structure, which is expressed as:

Weight $_{\text {ini }}=\sum_{i=1}^{N O E} \rho L_{i} A_{i}$

where $N O E, \rho, L$ and $A$ are the number of elements, steel density, length and area of the elements, respectively.

\subsection{Variables}

The cross section of the beams and columns is i-shaped, which include parameters such as height of web, thickness of web, width of flange, thickness of flange, and also there is another parameter called tapered length ratio (TLR) in the beams. Among these parameters, the height of web, the thickness of web and tapered length ratio are considered as a variable, and the other parameters have a constant value. The values that these variables can have are shown in Table 1 .

\subsection{Constraints}

a. The strength of the structural elements is that the load on each element should not violate Eq. (1) or Eq. (2).

b. The criterion of construction requires the Eq. (3) and Eq. (4) not to be violated.

c. The displacement of the frames should be limited to the following values:

$\delta_{v a}-\frac{L}{360}<0$ for dead loads

$\delta_{v a}-\frac{L}{240}<0$ for live and dead loads

$\delta_{h}-\frac{h}{200}<0$ for lateral loads

where $\delta_{v a}$ and $\delta_{h}$ are vertical displacement of apex and lateral displacement of the frame, respectively. $L$ and $h$ are half-span length and height of column which are defined in Fig. 1. 


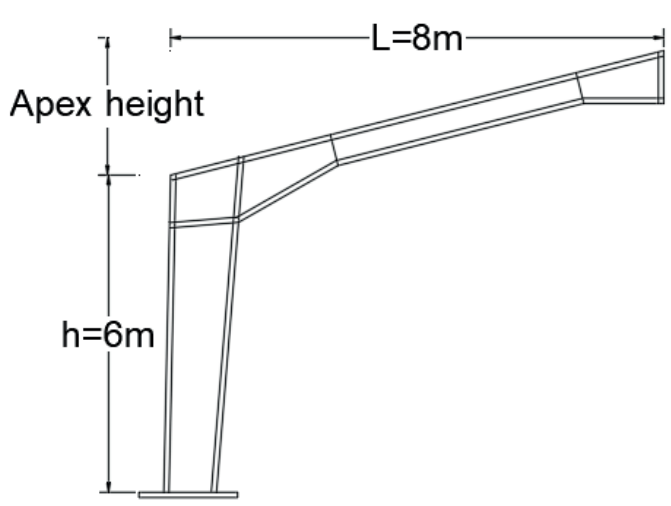

Fig. 1 Geometric parameters of half span in both frames

\section{Optimization algorithms}

The meta-heuristic algorithms search optimal solution among all the available solutions, Kaveh [13]. These algorithms perform this with trial and error approach. At each stage, new solutions are generated using the result of the previous steps. The difference between different meta-algorithms is how to generate a new answer. The meta-algorithms convert constrained problems using the penalty function to unconstrained problems. For this reason, it is better to use them for problems that have complex constraints. Some applications of meta-heuristic algorithm can be found in $[14,15,16]$. The selected meta-heuristic algorithms used in this paper are from the well-established and widely used meta-heuristics. This can be seen from the comparative studies performed in literature [13].

\subsection{Teaching-Learning Based Optimization}

TLBO is a nature-based inspired algorithm. This method focuses on the relationship between teacher and students in the classroom. This method has two phases. In the first phase, the relationship between teacher and students is simulated, and in the next phase, the relationship between a student and another student is simulated. In the first phase, the initial answer, which has the best objective function, is chosen as a teacher, and in the next step, new students are created using the following equation:

$$
X^{\text {new }, i}=X^{i}+r\left(X_{\text {teacher }}-T_{F} X_{\text {mean }}\right)
$$

where $X^{n e w, i}$ and $X^{i}$ are the new and existing $i$ th solution, $r$ is a random number varying $[0,1], T_{F}$ is a teaching factor being either 1 or 2 , and $X_{\text {mean }}$ is the mean of the solutions, Togan [17].

In phase II, each student randomly communicates with another student, and new students are created with the help of the following equations:

$$
\begin{array}{lll}
X^{\text {new }, i}=X^{i}+r\left(X^{i}-X^{j}\right) & \text { if } & f_{\left(X^{i}\right)}<f_{\left(X^{j}\right)} \\
X^{\text {new }, i}=X^{i}+r\left(X^{j}-X^{i}\right) & \text { if } & f_{\left(X^{i}\right)}>f_{\left(X^{j}\right)}
\end{array}
$$

where $X^{j}$ is the any solution to be different from $X^{i}$.

Finally, if the new student is better than the previous one, it will be replaced.

\subsection{Colliding Bodies Optimization}

This technique uses a body collision to make new answers, and in the feasible solutions space, it searches for the optimal answer. The initial answers are divided into two groups. The answers are sorted in increasing order, the first half of those who have better answers, are the stationary group and the second half of the group are moving. According to the energy and momentum laws, the speed of each body depends on the speed of the moving body and the mass of each body. New solutions are made as follows:

$X_{i}^{\text {new }}=X_{i-\frac{n}{2}}+\operatorname{rand} \cdot v_{i}^{\prime}, \quad i=\frac{n}{2}+1, \ldots, n$

where $X_{i}^{\text {new }}$ and $v_{i}^{\prime}$ are the new position and the velocity after the collision of the ith moving $\mathrm{CB}$, respectively; $X_{i-\frac{n}{2}}$ is the old position of the ith stationary CB pair, Kaveh \& Mahdavi [18].

$X_{i}^{\text {new }}=X_{i}+\operatorname{rand} \cdot v_{i}^{\prime}, \quad i=1, \ldots, \frac{n}{2}$

where $X_{i}^{\text {new }}, X_{i}$ and $v_{i}^{\prime}$ are the new position, old position and the velocity after the collision of the $i$ th stationary $\mathrm{CB}$, respectively. rand is a random vector uniformly distributed in the range $(1,1)$, Kaveh \& Mahdavi [18].

\subsection{Enhanced Colliding Bodies Optimization}

Enhanced Colliding Bodies Optimization (ECBO) is an advanced version of the $\mathrm{CBO}$ that uses a memory to save a number of historically best CBs and also utilizes a mechanism to escape from local optima, Kaveh and Ilchi Ghazaan [19]. Utilizing this enhanced version requires to specify the colliding memory size and a random parameter.

\subsection{Vibrating Particles System}

The VPS is a population-based algorithm which simulates a free vibration of single degree of freedom systems with viscous damping, Kaveh \& Ilchi Ghazaan [20]. In this method, three groups of answers are used to generate new answers: The historically best position of the entire population $(H B)$, a good particle $(G P)$, and a bad particle $(B P)$. 
To measure the effect of the damping level on the vibration, the parameter $D$ is defined. And the equations for generating the new answers are as follows:

$$
\begin{aligned}
& X_{i}^{j}=w_{1} \cdot\left[D \cdot A \cdot \text { rand } 1+H B^{j}\right] \\
& +w_{2} \cdot\left[D \cdot A \cdot \text { rand } 2+G P^{j}\right]+w_{3} \cdot\left[D \cdot A \cdot \text { rand } 3+B P^{j}\right], \\
& A=\left[w_{1} \cdot\left(H B^{j}-X_{i}^{j}\right)\right]+\left[w_{2} \cdot\left(G P^{j}-X_{i}^{j}\right)\right] \\
& +\left[w_{3} \cdot\left(B P^{j}-X_{i}^{j}\right)\right], \\
& w_{1}+w_{2}+w_{3}=1
\end{aligned}
$$

where $X_{i}^{j}$ is the $j$ th variable of the particle $i . w_{1}, w_{2}$, and $w_{3}$ are three parameters to measure the relative importance of $H B, G P$ and $B P$, respectively. rand 1 , rand 2 , and rand 3 are random numbers uniformly distributed in the range of $[0,1]$, Kaveh \& Ilchi Ghazaan [21].
Sometimes, for increasing the speed of the convergence, the $B P$ effect is considered in the update of the answers, and in each particle with probability $\rho, w_{3}=0$ and $w_{2}=1-w_{1}$.

\subsection{Harmony search}

Harmony Search (HS) is based on finding the best harmony by musicians, Geem et al. [22]. In this method, the generation of new solutions is more diverse than other methods and shows that its performance is better than other methods in finding the optimal global response. In this algorithm, each of the solution variables can be selected from the harmony memory with the probability of $H M C R$ (harmony memory consideration rate), and with the probability of 1 . HMCR is randomly selected. Also, each new answer can be changed with the probability of $P A R$ (pitch adjustment rates), by the following equations, or not changing with the probability of 1-PAR.

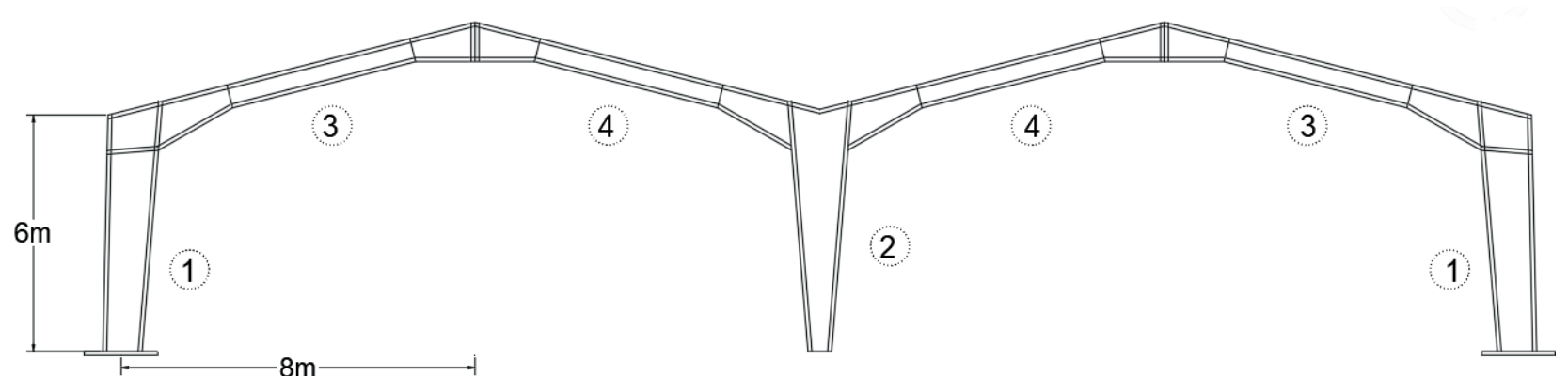

Fig. 2 Element groups of the 2 spans frame

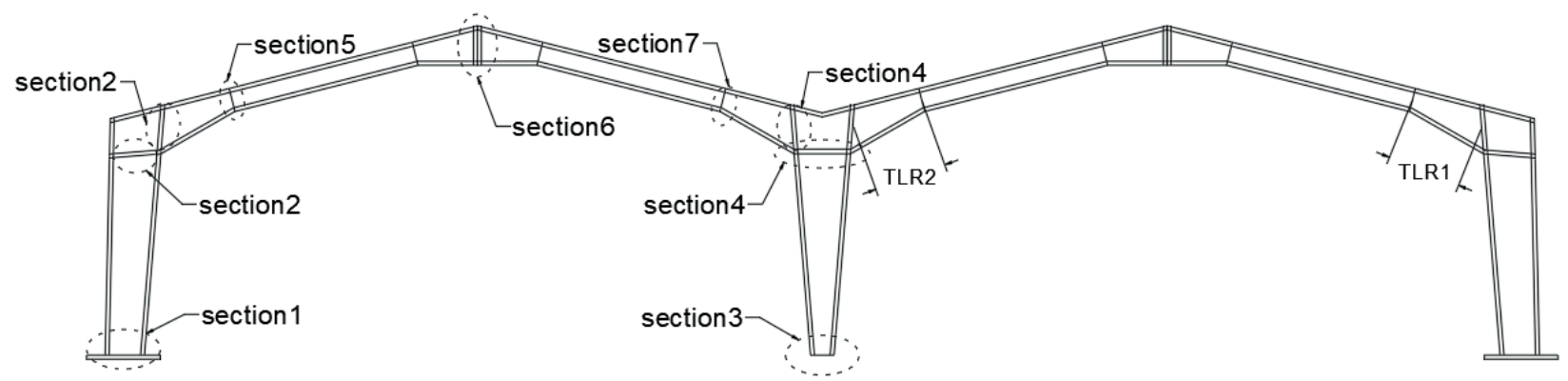

Fig. 3 Variables of the 2-span frame

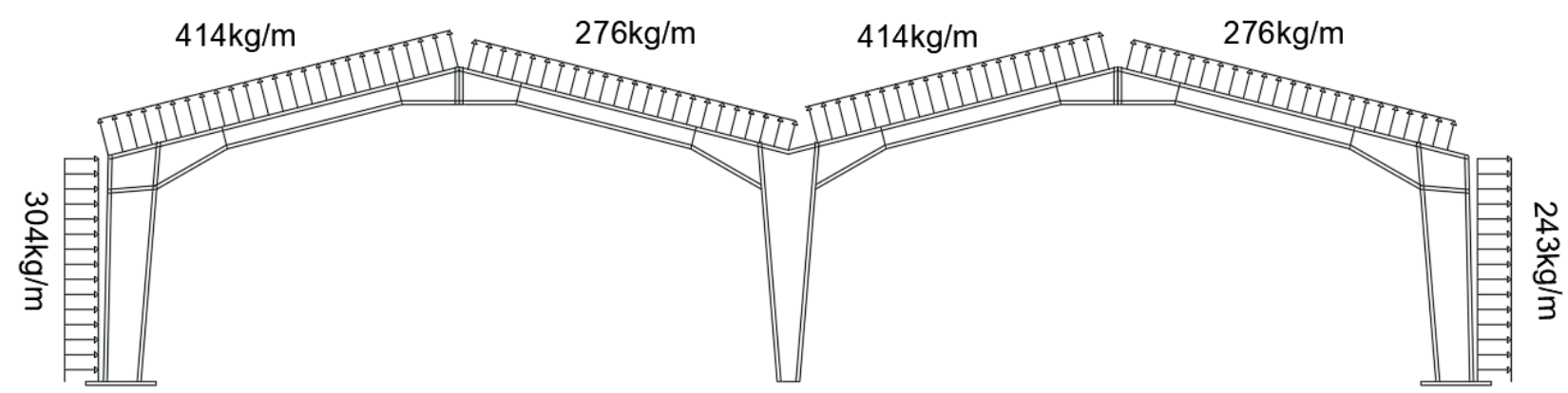

Fig. 4 Wind load on the 2-span frame 
$X_{i}^{j}=X_{i}^{j} \pm \delta$

$\delta=F W^{*}$ rand

$F W=0.1 *($ VarMax - VarMin $)$

where $X_{i}^{j}$ is the $j$ th variable of the harmony i. $F W$ is fret width, and VarMax, VarMin are the maximum and minimum bounds of the variables, respectively.

\section{Numerical examples}

Two examples are studied in this section. In the first example, the frame has two spans, and the number of elements group is four, and for the second example the frame has three spans and five groups of elements. MATLAB software is used for modeling the optimization process. SAP2000 - software is utilized for modeling, analysis and design of the structures. The modulus of elasticity of steel and its yield stress is $2039000 \mathrm{~kg} / \mathrm{m}^{2}$ and $2531 \mathrm{~kg} / \mathrm{m}^{2}$ respectively. The parameters of the algorithms are determined as follows:

TLBO: In this algorithm, $T f$ (teaching factor) can be 1 or 2 and randomly selected between 1 and 2 .

CBO: This algorithm depends on no internal parameter.

ECBO: In this algorithm, colliding memory size and random number are 6 and 0.6 , respectively.

VPS: The probability of considering the effect of $B P$ in updating is 0.3 . Harmony memory consideration rate, pitch adjustment rate and neighbor are $0.95,0.1$ and 0.1 , respectively. Also, $\alpha, w 1, w 2$ and $w 3$ are $0.05,0.3,0.3$ and $1-w 1-w 2$, respectively.
HS: Harmony memory consideration rate, pitch adjustment rate and fret width damp ratio are $0.85,0.1$ and 0.995 , respectively.

To compare the performance of algorithms, a frame is optimized with different algorithms, and their results are compared, for both examples. Then the effect of increasing the apex height on the optimal weight of the two-span and three-span frames are evaluated.

\subsection{Example 1}

In this example, in the first step, a frame with an apex height of $8.1 \mathrm{~m}$ and a span length of 16 meters with different algorithms is optimized and the results are compared. The optimal weights of each of the algorithms are shown in Table 2. Then, the frames with different apex heights and the same length of span are optimized, and the effect of increasing the apex height of the frame is evaluated on the optimum weight. Minimum and maximum apex heights are considered as $6.5 \mathrm{~m}$ and $8.5 \mathrm{~m}$ resulting in $3.58^{\circ}$ and $17.35^{\circ}$ for the minimum and maximum roof angle, respectively. In Example 1, the columns are in two groups of elements and the beams are also in two groups, and element groups are shown in Fig. 2. Frame dimensions and problem variables are shown in Figs. 1 and 3, respectively. The feasible range for variables is shown in Table 1. Roof gravity distributed loads, including dead, live and snow loads, are 480, 576, and 900, respectively. Seismic load is considered as 150 - and $100-\mathrm{kg} / \mathrm{m}$ uniformly distributed load on the $\mathrm{X}$ direction in the rafter and column, respectively. Wind load is considered in accordance with

Table 2 Optimum weight of different algorithms

\begin{tabular}{|c|c|c|c|c|c|}
\hline & HS & VPS & $\mathrm{CBO}$ & ECBO & TLBO \\
\hline Number of analysis & 960 & 960 & 960 & 960 & 1920 \\
\hline Best Cost (kg) & 3323.48 & 3324.77 & 3444.92 & 3335.2 & 3305.93 \\
\hline Mean Cost (kg) & 3323.48 & 3324.77 & 3444.92 & 3335.2 & 3308.3 \\
\hline Worst Cost (kg) & 3323.48 & 3324.77 & 3444.92 & 3335.2 & 3313.3 \\
\hline SD & 0 & $1.36 \mathrm{E}-12$ & 0 & 0 & 5.02 \\
\hline
\end{tabular}

Table 3 Optimum weights for different roof angles

\begin{tabular}{cc}
\hline Apex height $(\mathrm{m})$ & Optimum weight $(\mathrm{kg})$ \\
\hline 6.5 & 3090.57 \\
6.9 & 3145.25 \\
7.3 & 3168.83 \\
7.7 & 3262.92 \\
8.1 & 3305.93 \\
8.5 & 3408.66 \\
\hline
\end{tabular}


Table 4 Optimum value of the variables

\begin{tabular}{|c|c|c|c|c|c|c|c|c|c|c|}
\hline Apex height (m) & $\mathrm{TLR}_{1}(\%)$ & $\mathrm{TLR}_{2}(\%)$ & $\mathrm{h}_{1}(\mathrm{~m})$ & $\mathrm{h}_{2}(\mathrm{~m})$ & $\mathrm{h}_{3}(\mathrm{~m})$ & $\mathrm{h}_{4}(\mathrm{~m})$ & $\mathrm{h}_{5}(\mathrm{~m})$ & $\mathrm{h}_{6}(\mathrm{~m})$ & $\mathrm{h}_{7}(\mathrm{~m})$ & $\operatorname{Tw}(\mathrm{m})$ \\
\hline 6.5 & 15 & 40 & 0.4 & 0.6 & 0.4 & 1 & 0.4 & 0.4 & 0.4 & 0.008 \\
\hline 6.9 & 25 & 30 & 0.4 & 0.8 & 0.4 & 0.9 & 0.4 & 0.4 & 0.4 & 0.008 \\
\hline 7.3 & 20 & 35 & 0.4 & 0.7 & 0.4 & 0.9 & 0.4 & 0.6 & 0.4 & 0.008 \\
\hline 7.7 & 25 & 35 & 0.5 & 0.8 & 0.4 & 1 & 0.4 & 0.4 & 0.4 & 0.008 \\
\hline 8.1 & 25 & 35 & 0.5 & 0.8 & 0.4 & 1 & 0.4 & 0.5 & 0.4 & 0.008 \\
\hline 8.5 & 20 & 35 & .5 & .8 & .4 & 0.9 & .4 & 0.9 & 0.4 & 0.008 \\
\hline
\end{tabular}

Where $h_{1}, h_{2}, h_{3}, h_{4}, h_{5}, h_{6}$ and $h_{7}$ are the height of sections $1,2,3,4,5,6$ and 7 , respectively.

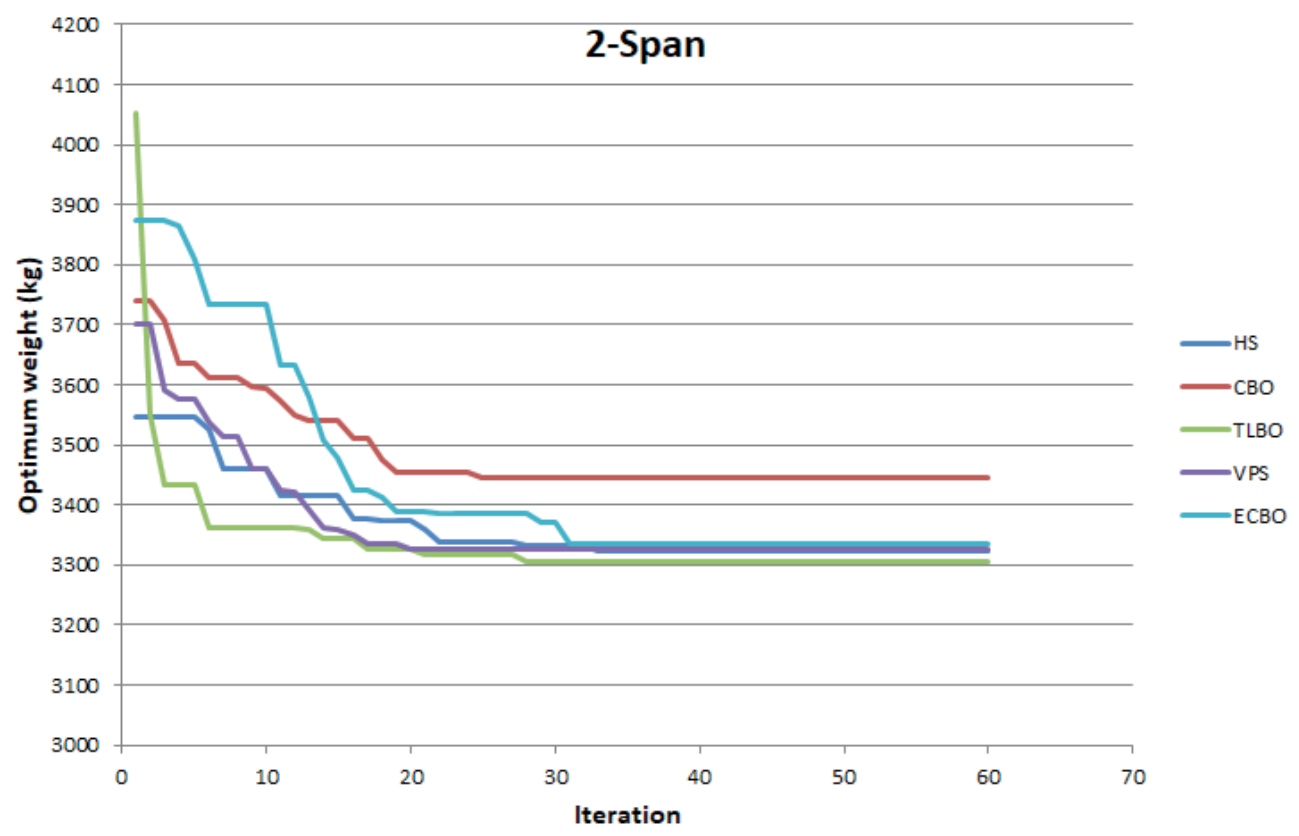

Fig. 5 Comparison of the convergence histories for the utilized algorithms

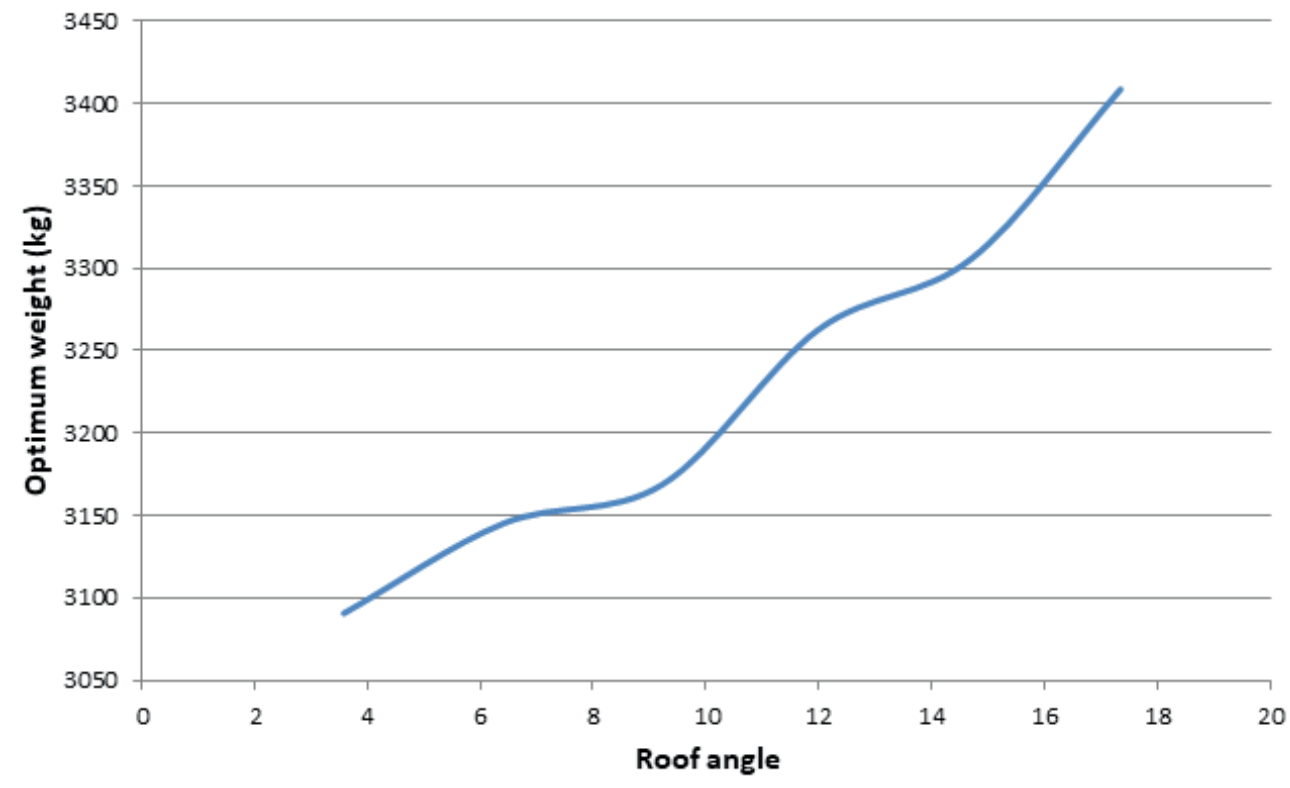

Fig. 6 Optimum weight of the frames with 2 spans in terms of the roof angle 
Fig. 4. The optimum weights of the frames with different roof angles are given in Table 3. The optimal values for variables for each roof angle is provided in Table 4 . The optimal weight of frames in terms of the roof angles is shown in Fig. 6. The population size and the number of iterations for all algorithms are 16 and 60 , respectively.

\subsection{Example 2}

In this example, the frame with three spans is evaluated. The number of element groups in this frame is five as shown in Fig. 7. Variables of the frame are shown in Fig.
8. Also, the wind load is illustrated in Fig. 9. Gravity and seismic loads and load combinations are the same as in the previous example. Initially, the frame with an apex height of 7.7 meters has been optimized using various algorithms and their results are compared in Fig. 10. Also, the optimal weights of the algorithms are provided in Table 5 . Then, the optimal weight of the frames is determined with different apex height, and their results are shown in Table 6. The optimal weight of the frames with three spans in terms of the roof angle is shown in Fig. 11. The optimal values for variables at each roof angle are shown in Table 7.

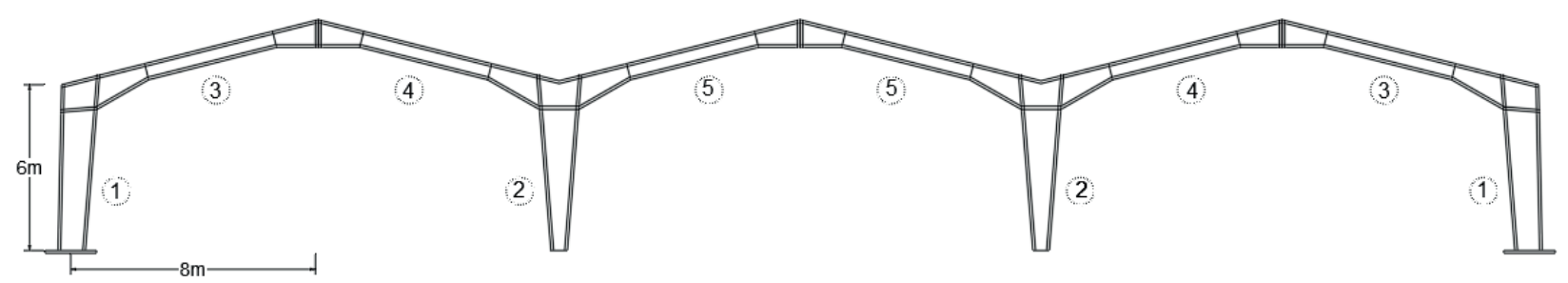

Fig. 7 Element groups of the 3-span frame

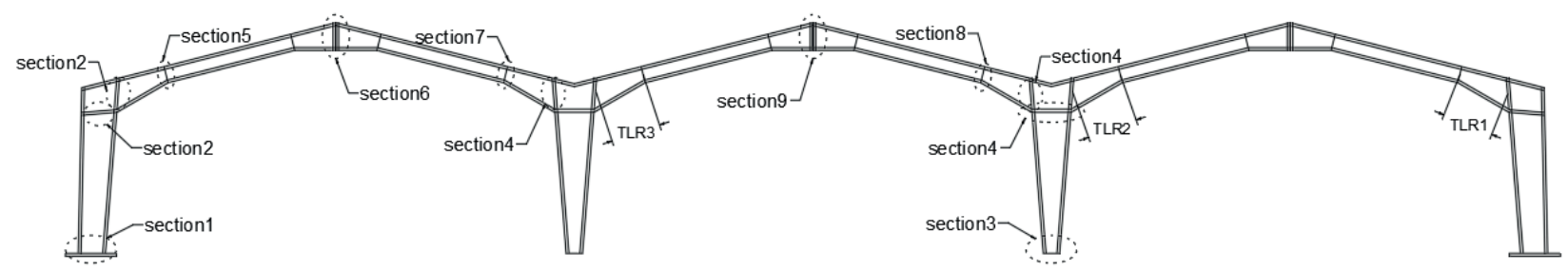

Fig. 8 Variables of the 3-span frame

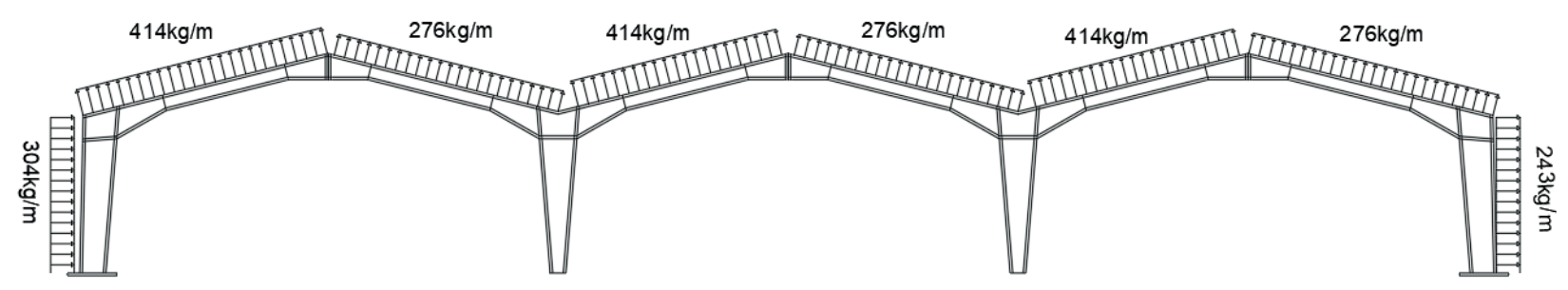

Fig. 9 Wind load on the 3-span frame

Table 5 Optimum weight of each algorithm for the frame with 3 spans

\begin{tabular}{lcccc}
\hline & HS & VPS & CBO & ECBO \\
\hline Number of analysis & 1560 & 1560 & 1560 & 1560 \\
Best Cost (kg) & 4891.647 & 4898.329 & 4867.67 & 4831.34 \\
Mean Cost (kg) & 4908.509 & 4907.2 & 4867.67 & 4864.71 \\
Worst Cost (kg) & 4928.341 & 4978.7 & 4867.67 & 5015.51 \\
SD & 12.3 & 17.24 & 0 & 4869 \\
\hline
\end{tabular}


Table 6 Optimum weight for each apex height for the frame with 3 spans

\begin{tabular}{cc}
\hline Apex height $(\mathrm{m})$ & Optimum weight $(\mathrm{kg})$ \\
\hline 6.5 & 4491.44 \\
6.9 & 4603.666 \\
7.3 & 4738.66 \\
7.7 & 4831.34 \\
8.1 & 4946.282 \\
8.5 & 5001.68 \\
\hline
\end{tabular}

Table 7 Optimum value of the variables for the frame with 3 spans

\begin{tabular}{lccccccccccccc}
\hline Apex height $(\mathrm{m})$ & $\mathrm{TLR}_{1}$ & $\mathrm{TLR}_{2}$ & $\mathrm{TLR}_{3}$ & $\mathrm{~h}_{1}(\mathrm{~m})$ & $\mathrm{h}_{2}(\mathrm{~m})$ & $\mathrm{h}_{3}(\mathrm{~m})$ & $\mathrm{h}_{4}(\mathrm{~m})$ & $\mathrm{h}_{5}(\mathrm{~m})$ & $\mathrm{h}_{6}(\mathrm{~m})$ & $\mathrm{h}_{7}(\mathrm{~m})$ & $\mathrm{h}_{8}(\mathrm{~m})$ & $\mathrm{h}_{9}(\mathrm{~m})$ & $\mathrm{Tw}(\mathrm{m})$ \\
\hline 6.5 & 20 & 30 & 30 & 0.4 & 0.7 & 0.4 & 0.9 & 0.4 & 0.5 & 0.4 & 0.4 & 0.4 & 0.008 \\
6.9 & 20 & 30 & 40 & 0.4 & 0.7 & 0.4 & 0.9 & 0.4 & 0.5 & 0.5 & 0.4 & 0.4 & 0.008 \\
7.3 & 15 & 35 & 30 & 0.5 & 0.8 & 0.4 & 0.9 & 0.5 & 0.6 & 0.4 & 0.4 & 0.5 & 0.008 \\
7.7 & 20 & 40 & 30 & 0.6 & 0.9 & 0.4 & 0.9 & 0.4 & 0.6 & 0.4 & 0.4 & 0.6 & 0.008 \\
8.1 & 25 & 40 & 40 & 0.6 & 0.9 & 0.4 & 1 & 0.4 & 0.6 & 0.4 & 0.4 & 0.4 & 0.008 \\
8.5 & 30 & 35 & 40 & 0.7 & 1 & 0.4 & 1 & 0.4 & 0.4 & 0.4 & 0.4 & 0.4 & 0.4 \\
\hline
\end{tabular}

Where $h_{1}, h_{2}, h_{3}, h_{4}, h_{5}, h_{6}, h_{7}, h_{8}$ and $h_{9}$ are the height of sections $1,2,3,4,5,6,7,8$ and 9 , respectively.

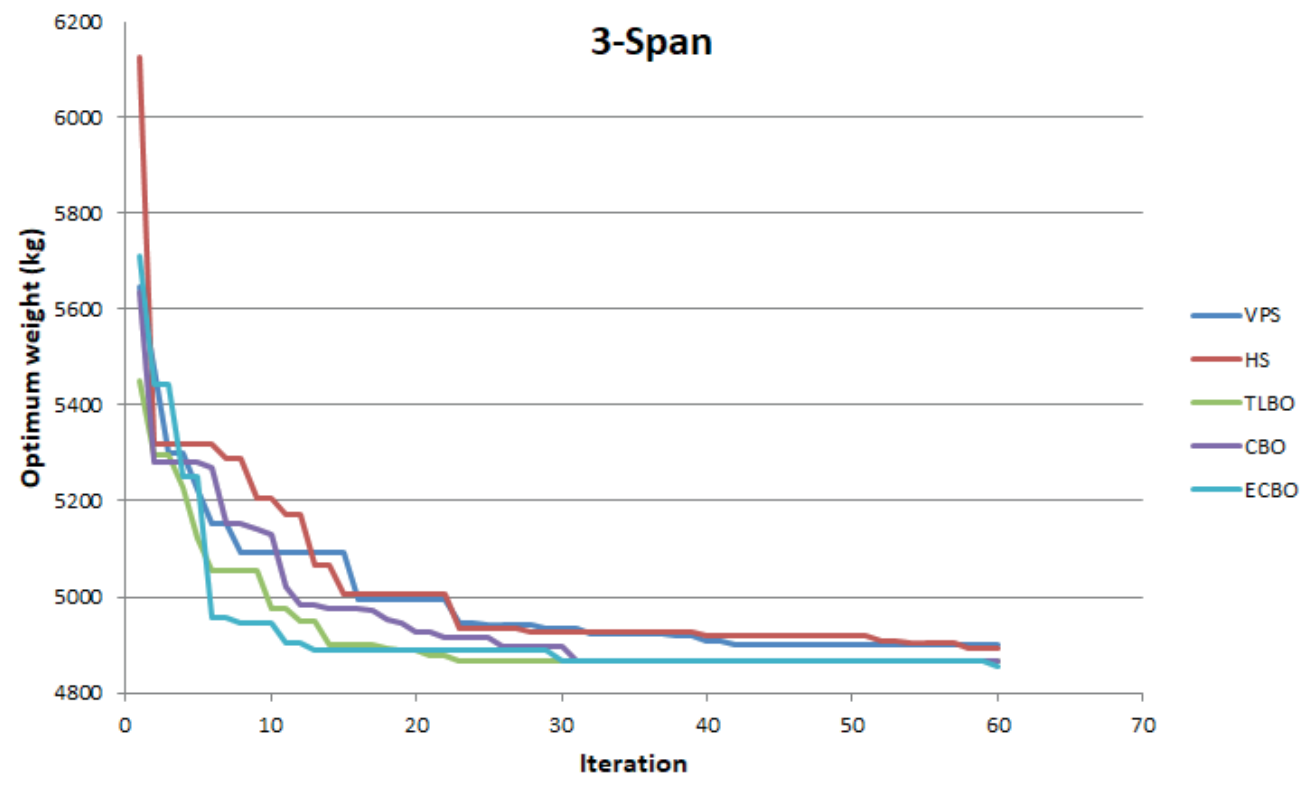

Fig. 10 Comparison of the convergence histories for the utilized algorithms

\section{Conclusions}

Optimization of the non-prismatic multi-spans frame with different apex heights is performed using different algorithms. In the first example, the two-span frame was optimized with various algorithms, which showed that the performance of all algorithms is appropriate. Then, the effect of increasing the roof angle on the optimum weight of the frame was investigated, showing that the best optimum weight in this frame occurs at the roof angle 3.580. In the second example, the three-span frame was optimized with different algorithms, and the best optimum weight was obtained by the ECBO algorithm and other algorithms had $0.6-1.3 \%$ difference with the best solution. Also, the effect of increasing the roof angle on the optimum weight of the frame was investigated. In this frame, the best roof angle for optimum weight is around 3.58o. In both frames, critical load combination was $1.2 \mathrm{DL}+1.6 \mathrm{SLR}+0.5 \mathrm{WL}$, indicating that the gravity load has the greatest impact in determining the size of the frame elements. 


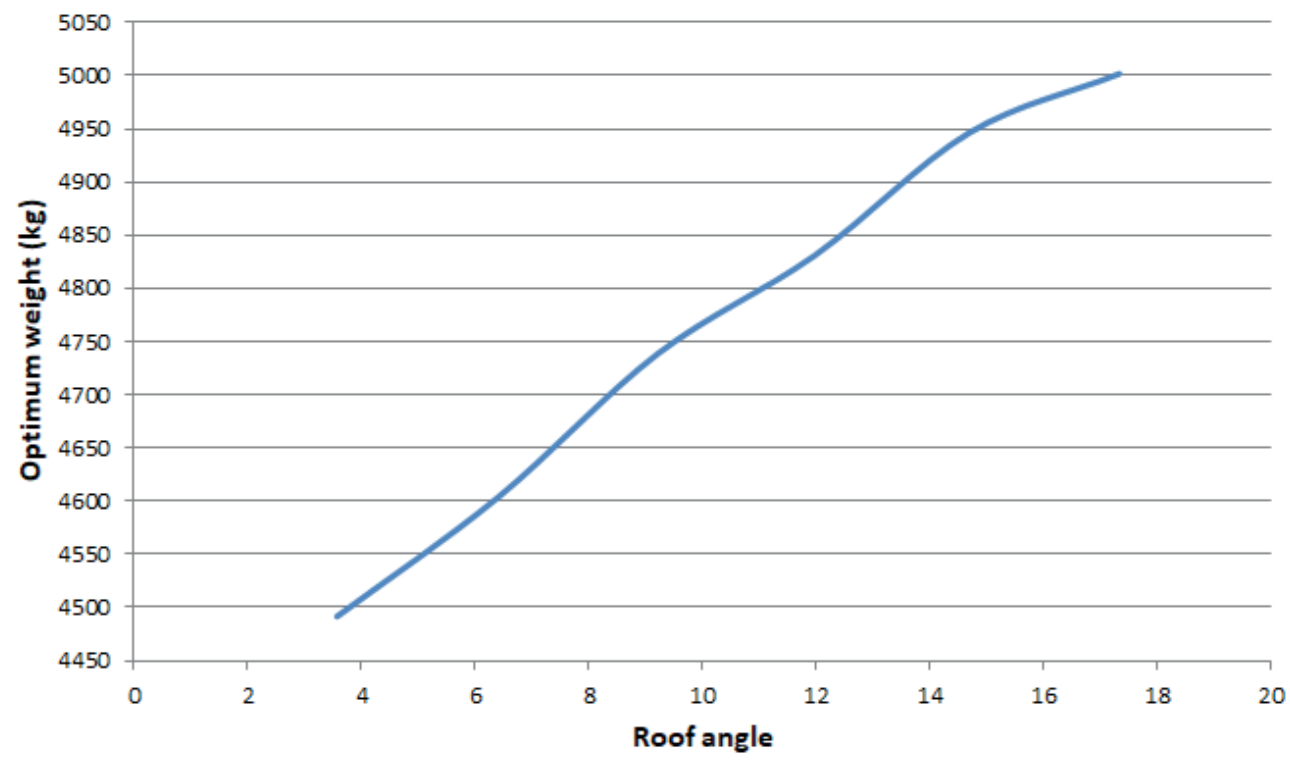

Fig. 11 Optimum weight of frames with three spans in terms of the roof angle

\section{References}

[1] O'Brien, E. J., Dixon, A. S. "Optimal plastic design of pitched roof frames for multiple loading", Computers and Structures, 64(1-4), pp. 737-740, 1997.

[2] Fraser, D. J. "Design of tapered member portal frames", Journal of Constructional Steel Research, 3(3), pp. 20-26, 1983. https://doi.org/10.1016/0143-974X(83)90003-2

[3] Phan, D. T., Lim, J. B. P., Tanyimboh, T. T., Lawson, R. M., Xu, Y., Martin, S., Sha, W. "Effect of serviceability limits on optimal design of steel portal frames", Journal of Constructional Steel Research, 86, pp. 74-84. 2013.

https://doi.org/10.1016/j.jcsr.2013.03.001

[4] Phan, D. T., Lim, J. B. P., Ming, C. S. Y., Tanyimboh, T., Issa, H., Sha, W. "Optimization of cold-formed steel portal frame topography using real-coded genetic algorithm", Procedia Engineering, 14, pp. 724-733, 2011. https://doi.org/10.1016/j.proeng.2011.07.092

[5] Saka, M. P. "Optimum design of pitched roof steel frames with haunched rafters by genetic algorithm", Computers and Structures, 81(18-19), pp. 1967-1978, 2003. https://doi.org/10.1016/S0045-7949(03)00216-5

[6] Kravanja, S., Turkalj, G., Šilih, S., Žula, T. "Optimal design of single-story steel building structures based on parametric MINLP optimization", Journal of Constructional Steel Research. 81, pp. 86-103, 2013.

https://doi.org/10.1016/j.jcsr.2012.11.008

[7] Avdelas, A. V. "A program for the elasto-plastic analysis and design of haunched steel frames", Computers and Structures, 45(1), pp. 61-68, 1992.

https://doi.org/10.1016/0045-7949(92)90345-Z

[8] McKinstray, R., Lim, J. B. P., Tanyimboh, T. T., Phan, D. T., Sha, W. "Optimal design of long-span steel portal frames using fabricated beams", Journal of Constructional Steel Research, 104, pp. 104-114, 2015.

https://doi.org/10.1016/j.jcsr.2014.10.010
[9] Kaveh, A., Mahdavi, D. V. R., Kamalinejad, M. "Optimal design of pitched roof frames with tapered members using ECBO algorithm", Smart Structures and Systems, 19(6), pp. 643-652, 2017. https://doi.org/10.12989/sss.2017.19.6.643

[10] Kaveh, A., Gafari, M. H. "Geometry and sizing optimization of steel pitched roof frames with tapered members using nine metaheuristics", Iranian Journal of Science and Technology, 3(12), pp. 1-8, 2018. https://doi.org/10.1007/s40996-018-0132-1

[11] ASCE, "ASCE/SEI 7-10 Minimum design loads for buildings and other Structures", Reston, Virginia, USA, 2015.

[12] AISC, "AISC 360-05-Specification for structural steel buildings", Chicago, Illinois, USA, 2005.

[13] Kaveh., A. "Advances in metaheuristic algorithms for optimal design of structures", 2nd ed., Springer International Publishing, Basel, Switzerland, 2017.

[14] Kaveh, A., Zolghadr, A. "Magnetic charged system search for structural optimization", Periodica Polytechnica Civil Engineering, 58(3), pp. 203-216, 2014. https://doi.org/10.3311/PPci.7460

[15] Kaveh, A., Farhoudi, N. "Layout optimization of braced frames using differential evolution algorithm and dolphin echolocation optimization", Periodica Ploytechnic Civil Engineering, 59(3), pp. 441-449, 2015 https://doi.org/10.3311/PPci.8155

[16] Kaveh, A., Mahdavi, V. R., Kamalinejad, M. "Optimal design of the monopole structures using CBO and ECBO algorithms", Periodica Polytechnica Civil Engineering, 61(1), pp. 110-116, 2017. https://doi.org/10.3311/PPci.8546

[17] Toğan, V. "Design of planar steel frames using teaching-learning based optimization", Engineering Structures, 34, pp. 225-232, 2012. https://doi.org/10.1016/j.engstruct.2011.08.035

[18] Kaveh, A., Mahdavi, V. R. "Colliding bodies optimization: a novel meta-heuristic method", Computers \& Structures, 139, pp. 18-27, 2014.

https://doi.org/10.1016/j.compstruc.2014.04.005 
[19] Kaveh, A., Ilchi Ghazaan, M. "Enhanced colliding bodies optimization for design problems with continuous and discrete variables", Advances in Engineering Software, 77, pp. 66-75, 2014. https://doi.org/10.1016/j.advengsoft.2014.08.003

[20] Kaveh, A., Ilchi Ghazaan, M. "Vibrating particles system algorithm for truss optimization with multiple natural frequency constraints", Acta Mechanica, 228(1), pp.307-322, 2017.

https://doi.org/10.1007/s00707-016-1725-z
[21] Kaveh, A., Ilchi Ghazaan, M. "Truss optimization with dynamic constraints using UECBO", Advances in Computational Design, 1(2), pp. 119-138, 2016. https://doi.org/10.12989/acd.2016.1.2.119

[22] Geem, Z. W., Kim, J. H., Loganathan, G. V. "A new heuristic optimization algorithm: harmony search", Simulation, 76(2), pp. $60-68,2001$

https://doi.org/10.1177/003754970107600201 